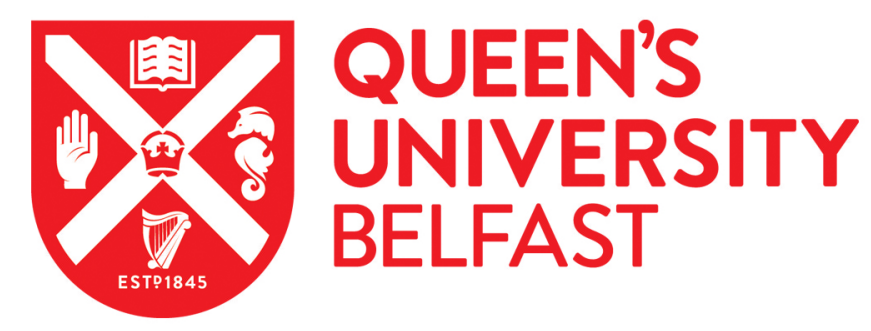

\title{
Usefulness of Species Traits in Predicting Range Shifts
}

Estrada, A., Morales-Castilla, I., Caplat, P., \& Early, R. (2016). Usefulness of Species Traits in Predicting Range Shifts. Trends in Ecology \& Evolution, 31(3), 190-203. https://doi.org/10.1016/j.tree.2015.12.014

\section{Published in:}

Trends in Ecology \& Evolution

\section{Document Version:}

Peer reviewed version

Queen's University Belfast - Research Portal:

Link to publication record in Queen's University Belfast Research Portal

Publisher rights

(c) 2016 Elsevier Ltd. All rights reserved.This work is made available online in accordance with the publisher's policies. Please refer to any applicable terms of use of the publisher.

\section{General rights}

Copyright for the publications made accessible via the Queen's University Belfast Research Portal is retained by the author(s) and / or other copyright owners and it is a condition of accessing these publications that users recognise and abide by the legal requirements associated with these rights.

Take down policy

The Research Portal is Queen's institutional repository that provides access to Queen's research output. Every effort has been made to ensure that content in the Research Portal does not infringe any person's rights, or applicable UK laws. If you discover content in the Research Portal that you believe breaches copyright or violates any law, please contact openaccess@qub.ac.uk. 
1 Usefulness of species traits in predicting range shifts

2 Alba Estrada ${ }^{1,2}$, Ignacio Morales-Castilla ${ }^{3}$, Paul Caplat ${ }^{4}$ and Regan Early*5

$4 \quad$ 1: $\mathrm{CIBIO} / \operatorname{InBIO}$, Universidade de Évora, Portugal

5 2: Department of Integrative Ecology. Estación Biológica de Doñana (EBD-CSIC). Sevilla,

6 Spain

7 3: Department of Biology, McGill University, Montréal, QC, Canada

8 4: Centre for Environmental and Climate Research, Lund University, Sweden

9 5: Centre for Ecology and Conservation, University of Exeter, Penryn Campus, Cornwall, UK.

10 Twitter: @ReganEarly

11

$12{ }^{*}$ Corresponding author: Early, R. (r.early@exeter.ac.uk). 
Abstract

Information on species' ecological traits might improve predictions of climate-driven range shifts. However, the usefulness of traits is usually assumed rather than quantified. We present a framework to identify the most informative traits, based on four key range-shift processes: (i) emigration of individuals or propagules away from the natal location, (ii) the distance a species can move, (iii) establishment of self-sustaining populations, and (iv) proliferation following establishment. We propose a framework that categorises traits according to their contribution to range-shift processes. We demonstrate how the framework enables the predictive value of traits to be evaluated empirically, how this categorisation can be used to better understand range shift processes, and illustrate how range shift estimates can be improved.

Predictive traits as a new paradigm in climate change ecology

Mitigating the threat from climate change to biodiversity and ecosystems requires a robust understanding of how species will respond to new climatic conditions. The most common method for estimating a species' exposure to climate change is to compare future climatic conditions against the conditions in which a species currently lives [1]. While there is disagreement about the accuracy of these techniques, they are well explored, and there is literature on best practice $[2,3]$. Species vulnerability to exposure is less well understood. A major uncertainty is whether species are able to colonise newly climatically suitable areas once current geographic ranges become unsuitable. Such "range shifts" (see Glossary) could 
37 Predictive traits have been suggested as a simple way to improve estimation of species' range-shift capacities, identifying how well species are likely to cope with climate change [47]. 'Range-shift capacity' could be interpreted as the likelihood of range shifts occurring or timescale over which range shifts might occur. The emerging approach is to integrate information on both a species' exposure to climate change and the traits expected to drive range-shift capacity, producing a relative metric of species risk [4-6]. The choice of predictive traits in these approaches is rarely based on quantitative evidence, and many studies rely on expert opinion and data availability $[4,6]$. The number of studies with different sets of traits can be overwhelming, and there is a need to clarify how different traits contribute to species range-shifts, and thus climate change threats, using the evidence accumulated over the past two decades. -

\section{A framework to evaluate and employ predictive traits}

In addition to climate change ecology, bodies of theory within metapopulation, invasion, life-history, restoration and reintroduction ecology deal with range shifts, i.e. the establishment and expansion of new populations. We draw from these disciplines to identify four key range shift processes (Box 1). Despite widespread acceptance of these range shift processes, their importance for any given taxa or range-shift scenario is poorly known. Traits could be used to indicate success at each range shift process, but the relevant traits are numerous and diverse, will differ between taxa, and are measured to varying degrees. This presents difficulties for evaluating the importance of a trait. We therefore propose a trait categorisation (Box 2) that corresponds to range shift processes. This categorisation results in testable hypotheses as to causal mechanisms underlying the 
relationship between traits and range shifts. The categorisation also allows trade-offs and interactions between traits to be recognised and accounted for. For example, migratory status could affect range-shift capacity positively by conferring high movement ability, or negatively by limiting emigration because migrants show fidelity to breeding and overwintering sites between years [8, 9, Box 2]. Categorisation permits the use of existing evidence bases to identify the most important traits and range shift processes for a given taxa, improved testing of the relationship between traits and range shifts, and superior assessments of the range-shift capacities of large numbers of species (Box 3). Given the hundreds of traits that could be analysed for different taxa, employing the categorisation we suggest based on the range-shift framework (Box 2) would permit future studies to be comparable. And while the evidence bases we discuss are correlative, choosing traits to analyse based on our framework would generate testable hypotheses as to causal mechanisms.

In addition to traits, various range shift stages might be affected by species' exposures to climate change and thus by species' climatic tolerances. Here we deal exclusively with how traits can be employed to improve range-shift predictions, but raise this issue in box 4 (Outstanding Questions).

\section{Evidence bases for the relevance of predictive traits to range-shift capacities}

There are multiple metrics for which a wealth of data exists that can be used to evaluate the predictive value of traits. Traits that correlate with biogeographical patterns and their changes through time are likely to be the same traits that correspond to the processes of climate-driven range shifts. Below we discuss potential metrics for evaluating predictive 
traits, summarize their advantages and disadvantages and the major lessons learned for the use of predictive traits in estimating range-shift potential. We illustrate these points with selected examples from the literature (Table 1). We focus on terrestrial systems, for which we found the most evidence as to the processes that drive range shifts.

\section{Recent range shift}

Detecting the traits shared by species that have undergone the greatest range shifts in recent decades is the most direct way to infer traits that will promote or hinder modern range shifts, which must also take place in tens to hundreds of years due to the current pace of climate change. However, analyses of traits that correspond to recent range shifts have yielded equivocal results [10-14] (Table 1). One explanation might be that the drivers of range shift are so complex that a few decades worth of data are insufficient to draw generalisations. A second explanation is that these analyses have rarely considered species' exposure to climate change. If no areas become newly climatically suitable no colonisation can occur, and if species can tolerate new conditions no range contraction will occur. It has often been difficult to calculate exposure due to challenges in obtaining accurate data on climatic tolerances for the species that have undergone range shifts (though see [14]). Where this is not possible, measuring shifts along environmental axes (e.g. climatic) should yield more insights than using only latitudinal or altitudinal shifts [15]. The requirement for data at multiple time points restricts this approach to a handful of very well-studied taxa and geographic regions, reinforcing biases that already exist in the climate change literature [16]. Despite these limitations, the few trends that have emerged correspond to results obtained using other biogeographical metrics (range size or range filling, see below, Glossary and Table 1). We therefore suggest that, while monitoring ongoing range shifts is 
highly important for understanding the predictive value of traits, proxies such as range filling and range size are also useful.

\section{Range size}

Widespread species with large ranges have colonised and maintained persistent populations over large areas [17], and should therefore be able to colonise and proliferate in newly climatically-suitable areas. This is particularly the case in regions where species ranges are substantially affected by historic climate change. For instance, in Europe, species' current ranges are largely determined by the degree to which species have been able to expand since the Last Glacial Maximum [18]. The traits that correlate with the range size of European species are therefore expected to be traits that have facilitated post-glacial range expansion [19]. Traits that correlate with Extent of Occupancy (EOO) would indicate the furthest distance at which new populations might be established, whereas traits that correlate with Area of Occupancy (AOO) would indicate the distance at which most populations will be established. A major caveat is the difficulty in distinguishing the degree to which range size is determined by species' capacities to colonise and persist in suitable areas, or by the availability of suitable environmental conditions. Range sizes could also be affected by historical biogeographical processes, and analytical techniques are emerging to quantify these effects [20]. These caveats also apply to range filling, below.

\section{Range filling}

The rationale behind the use of range filling to inform predictive traits is that, when potential range is calculated using suitable climatic conditions (using an SDM or physiological data $[2,3,21])$ unoccupied portions of the potential range must be due to nonclimatic range limitations (e.g. edaphic conditions, dispersal limitations, biotic interactions). 
Traits associated with range filling would therefore indicate vulnerability to current or historic non-climatic range limitations $[22,23]$, and thus inform species' vulnerability to similar limitations during modern range shifts [19]. However, range-filling reflects processes that occurred over thousands of years, some of which might not be at play in modern rangeshifts, due to the faster pace of current climate change. For example, biotic interactions like competitive exclusion are often more observable over long timescales [24, 25]. Therefore, traits that correspond to competitive ability might be more important to range filling than to modern range shifts; a hypothesis that could be tested using available evidence bases and our framework.

\section{Naturalisation potential}

Predictive traits are widely investigated as indicators of species' potential to naturalise, spread, and impact ecosystems following introductions by humans [26-28]. Similar ecological and evolutionary processes occur during climate change in the native region and during naturalisation, as species encounter novel climates and biotic communities [29]. Most of the world's many thousands of human-mediated naturalisations have occurred within the last 200 years, many within the last 50-100 years [30], i.e. a similar timescale to that over which the impacts of climate change on native species are normally considered [30]. However, most studies of predictive traits in naturalisation involve species classified as invasive [31]. The proportion of introduced species that are invasive is low, although there is not a general agreement (e.g. $1 \%$ [32] or $25 \%$ [33]). Thus, invasive species may not be representative of most species, in particular species that are rare as natives and thus of particular concern under climate change: traits related to invasion success are not the inverse of traits related to extinction risk [34]. Nonetheless, the vast majority of naturalised 
species do not become problematic or widespread invasives and are thus broadly representative, suggesting that tapping this information source would be valuable.

\section{Abundance shifts}

Examining changes in abundance across geographic space offers insights into population growth rate that cannot be gained by studying range (i.e. occurrence) shifts alone $[15,16]$. Abundance changes might occur before range shifts can be observed, and could give specific insight into the traits associated with establishment. The relationship between predictive traits and trends in abundance have been fairly well studied [35-37]. Traits related to abundance declines suggest susceptibility to anthropogenic stressors, which could in turn limit range-shift capacity, particularly in human dominated areas [38]. The heavy data demands for calculating population trends limit these data to a few countries and for conspicuous groups of species (Table 1). Recent research has investigated spatial abundance dynamics at the community level rather than focusing on individual species [e.g. 39]. This is particularly useful when individual species are rare or show only small abundance changes. However, community indices might mask hidden drivers or differences between species [40], and to our knowledge no study has yet linked them to predictive traits.

\section{Threat status}

Examining the traits that correspond to species' threat status is commonly done thanks to large, standardised datasets such as the IUCN Red List [41]. However, threat status is driven by a plethora of environmental stressors, of which climate change is a relatively recent factor. We consider threat status to be a weak proxy for species' range-shift capacities under climate change. Nonetheless this line of enquiry has generated much expertise and understanding of the relationship between traits and species vulnerability. 
Traits explaining distribution changes: what is done, and what could be done

177 Table 1 summarises 40 studies that are excellent examples of the above evidence bases because they analysed a large number of species from different taxa and a variety of traits from different regions. The studies were selected following criteria in Appendix S1 (section A), and include all metrics discussed above. There are two major hurdles to interpreting existing evidence bases. First, the suite of traits analysed rarely represent all processes that could drive either the response variable (metric of trait predictive value) or climate-driven range shifts (Box 1). This has limited the mechanistic insight that can be obtained, as links between traits and the response variable might be dependent on trade-offs and interactions with unmeasured traits [9]. Second, traits employed by different studies are not standardized between taxa, and often not within taxa [10]. The literature therefore does not yet permit a meta-analysis, but it is possible to identify high quality studies with broad taxonomic representation from which we can assess evidence for the importance of trait categories (Box 2). See box 2 and table for traits included in each category.

The taxa for which most trait-based analyses have been undertaken are plants, terrestrial vertebrate endotherms, and butterflies (Table 1). Geographic areas analysed are mainly in Europe and North America. Notably, fewer than half of the studies specify hypotheses for the ecological processes that could underlie the relationship between traits and the response variable [e. g. 19, 23, 42, 43].

Movement ability, ecological generalization and reproductive strategy were the most widely studied trait categories (Table 1). Movement and ecological generalization were identified as important more frequently than any other category. However, movement ability had a 
significant and positive effect in fewer than half of the cases it was studied. Thus, while the movement process is clearly a major determinant of range shift capacity, other range-shift processes also play an important role. Ecological generalization was found to have a positive effect in the majority of studies that assessed it, whereas reproductive strategy had a positive effect in a quarter of the cases in which it was studied. The equivocal support for reproductive strategy might be the result of trade-offs with other traits such as competitive ability or persistence in unfavourable climatic conditions [44].

Persistence in unfavourable climatic conditions is rarely studied, but the proportion of positive results in Table 1 suggests it should be considered in the future. For instance, Estrada et al. [19] found that seed bank persistence in plants was even more important than movement ability or ecological generalization in predicting range size and filling for plant species in Europe. For animals, hibernation has been hypothesised as improving range shifts by enabling individuals to avoid unfavourable conditions [10] (Box 2), but showed no predictive power (Table 1). No support was found for longevity (Box 2), possibly because longevity trades off with age of first reproduction, reflecting slower colonization [44]. Thus, traits that correspond clearly to persistence might be difficult to define for animals. Although rarely accounted for in range-shift forecasts, competitive ability was studied in 14 cases, and had a positive effect in nine. For plants there are well-established frameworks to evaluate competitiveness (e.g. the Competitor-Stress tolerator-Ruderal framework [44]) but there is as yet no corresponding framework for terrestrial animals. For animals therefore, we included traits in this category that correspond to dominance (e.g. local abundance), intra-generic co-occurring species richness (indicating the number of similar, potential competitor, species), and brain size (which corresponds to innovation, a key component of 
competition avoidance [27]). Given the surprisingly high importance for these traits, we recommend more work towards understanding the impacts of competition on species ranges.

The least studied and least supported trait categories in our sample were avoidance of small population effects, which corresponds to colonisation ability, and site (in)fidelity, which corresponds to emigration (Box 2). Categorising avoidance of small population effects in plants is fairly straightforward: self-fertilization and vegetative regeneration are key traits in this respect and are widely measured. However, in the papers we sampled for animals, relevant traits analysed were population or social group size, which could be too simplistic to capture complex outcomes of animal behaviour for small population sizes. We note that traits that correspond to reproductive strategies, which were important in some cases, could also contribute to avoidance of small population effects. The limited support for traits related to avoidance of small population effects could imply that the colonisation process might not strongly limit range shifts for the majority of taxa studied (Box 1). However, we investigation.

\section{Limitations of existing evidence bases}

It is important to remember that a lack of support in the evidence bases we sampled should not be taken to suggest that a given trait is not important for any species. Rather, positive or 
negative effects in Table 1 indicate evidence across many species that a given trait is sufficiently tightly linked to a range-shift process that it could be used to inform relative estimates of range-shift likelihood in multi-species analyses. A caveat to all correlative approaches we outline is that trait plasticity and evolution (past or ongoing) might obscure the relevance of traits to range shifts.

While trait data are becoming increasingly available, potentially important traits are often unavailable, e.g. movement distance in animals. Alternatives are to use values for congeneric species, or morphological proxies $[9,13,46]$. Increasing awareness of the usefulness of traits (particularly non-movement traits) to inform responses to climate change should stimulate collection and curation of potentially informative traits.

Macro-ecological analyses of predictive traits typically use a single trait value for the whole species (usually the mean of all recorded values) $[13,19]$, despite increasing evidence of substantial intraspecific variation [47, box 4: Outstanding Questions]. Whenever possible, the use of trait variance together with means can provide new insights and more accurate separation among species on their capacities for range shift. However, information on intraspecific variation is rarely available, so it is not yet possible to develop a comprehensive macro-ecological analysis for a large number of traits. Nevertheless, the findings in Table 1 indicate that characterizing species with single trait values does detect relative interspecific variation in metrics that correspond to range-shift capacity.

\section{Concluding remarks}


We encourage the use of predictive traits in assessment of species potential to colonise new areas in response to climate change. We recommend that all range-shift processes should be represented in the choice of traits, and we demonstrate how traits can be categorised in terms of their contribution to these processes and used to inform range shift potential. While correlative methods are still the main option for assessing predictive traits for large numbers of species, employing our framework would formalise hypotheses on the mechanistic underpinning of the relationship between trait and range shift. This would permit synthesis across studies and meta-analysis, ultimately leading to a broad understanding of how traits mediate range shift. While we encourage new analyses to improve understanding for different global regions, taxonomic groups, and under-studied movement, ecological generalization, persistence in unfavourable climatic conditions, reproductive strategy, and competitive ability should be considered for inclusion in rangeshift evaluations. Further experimental studies could use our proposed framework to better make mechanistic linkages between traits and range shifts and site persistence.

\section{Acknowledgments}

This research is funded by the ERA-Net BiodivERsA, with the national funder FCT, through the project BIODIVERSA/0003/2011. AE was funded by the project IF/00266/2013/CP1168/CT0001. IM-C is funded by the Fonds de Recherches du Québec Nature et Technologies (FQRNT) programme. PC is funded by the Swedish strategic research environment Biodiversity and Ecosystem Services in a Changing Climate (BECC). 


\section{Glossary}

291

AOO: area of occurrence, the geographic area that is actually occupied by a species [48], often defined as the number of occupied grid cells (which vary in size between atlases) [19].

Competitive ability: the ability of an individual of one species to reduce the availability of contested resources to an individual from another species, and to tolerate or avoid reduction in contested resource availability by an individual from another species [49].

Ecological generalization: the ability to use a wide variety of a given resource type, e.g., ecological generalists could breed in a wide variety of land cover types, have a broad diet, or tolerate a broad range of soil types.

Emigration: first range-shift process, in which an individual embarks on a journey

300 (movement) outside its natal location.

EOO: extent of occurrence, the area within the outer limits of the presence of the species $[43,48]$.

Establishment: range-shift process following movement, in which one or more individuals reproduce and found a self-sustaining population.

Indicative traits: species' characteristics related to environmental tolerance, habitat specialization, geographical boundaries or spatial distribution $[5,7,50]$. These traits can be measured at the individual or population level, so they are not life-history traits in strict sense. 
LHS framework: the theory that plant life-history strategy can be characterised by its position on three axes - " $L$ ", specific leaf area, " $H$ ", plant height at maturity, and " $S$ ", seed mass. Specific leaf area reflects variation in responsiveness to opportunities for rapid growth, whereas height and seed mass reflect separate aspects of coping with disturbance [51].

Life-history traits: those morphological, physiological or phenological characteristics measurable at the individual level that have an effect on individual performance [52].

Movement ability: ability of an individual or propagule to travel outside its natal location. This ability is often represented as the average or upper end of the distance moved in the lifetime of an individual or propagule. Note that this can be informed by, but is not restricted to, natal dispersal distances (movement from natal to breeding site). We specifically use 'movement ability' instead of 'dispersal ability' to avoid confusion, as the latter term is widely used to include emigration and establishment [53]. The movement process in dispersal has also been called transience, transport, and transfer [53].

Persistence in unfavourable climatic conditions: a population's capacity to survive during periods in which poor climate conditions leads to zero or negative population growth rate. Unfavourability could occur through climate change directly, or as a result of climatically induced changes in other elements of habitat suitability.

Potential range: the geographic area in which environmental conditions are suitable for a given species, even if the species is present or not. Potential range is generally calculated using SDMs. 
Predictive traits: we define predictive traits as any species' feature that can be used to predict (a) the likelihood and extent of range shift given exposure to climate change, or (b) the species' interactions with other species and non-climatic elements of the environment, which directly or indirectly affect range shifts. Predictive traits might include 'intrinsic' ecophysiological, life-history and demographic traits [52], as well as broader, nonorganismal 'indicative' features such as habitat requirements or spatial distribution $[5,7$, 10].

Proliferation: fourth range-shift process in which established populations become more than self-sustaining, producing individuals that will in turn disperse and cause further population spread.

Range filling: The proportion of its potential range that a species occupies.

Range shift: expansion of one part of the range margin following colonisation events. Range shift might or might not be accompanied by a contraction in another part of the range margin.

Reproductive strategy: the number, timing and degree of investment in each reproductive event, which are related to demography, fecundity and speed of life history. Species with an with a ' $\mathrm{K}$ ' strategy are older at first reproduction, have larger body mass and fewer offspring.

SDM: species distribution model. SDMs relate a species distribution with the environmental conditions in which species are found, in order to calculate environmentally suitable areas for that species. 
Site (in)fidelity: reflects the likelihood that an individual will embark on a dispersal event away from the natal patch. High site fidelity corresponds to a low likelihood of embarkation and thus low range-shift capacity. We therefore use 'site (in)fidelity' in line with the other six trait categories, for which the terms correspond to a positive effect on range-shift capacity.

Small population effects: factors that make it difficult for small populations to grow, and thus hinder population establishment. These include Allee effects, genetic drift, and susceptibility to demographic or environmental stochasticity.

\section{Box 1. Range-shift processes.}

The first range-shift process (see Figure I) is that individuals embark on a journey away from their natal location (emigration). For animals the motivations involved include high population density, low resource availability, and harassment from prospective mates [45].

For sessile taxa, such as plants, some aspects of reproductive behaviour can affect the probability that propagules disperse away from the adults' location, for example timing of seed shed to maximise dispersal by animals [54]. Species that have a physical or behavioural mechanism that promotes emigration are more likely to respond to poor environmental conditions (as driven by climate change) by leaving the natal location than those that do not have these mechanisms. Recent applications of metapopulation modelling approaches to climate change highlight the importance of emigration for range shifts [45, 55]. Movement itself, i.e. the transfer of individuals or propagules away from the location in which they originated, [55] is the second and most widely studied range-shift process. The upper limit of a species' dispersal distance is one of the strongest limitations on metapopulation 
persistence, invasive spread, and population recovery [56-58]. The third range-shift process

is establishment, i.e. the ability of dispersing individuals to reproduce and found new populations following a dispersal event. While probability of establishment is affected by the number of arriving propagules at a site, dispersal, invasion, and reintroduction ecology demonstrate that non-movement traits and their interaction with local conditions also mediate ease of establishment [59]. The fourth range-shift process is proliferation, i.e. the growth of established populations to become more than self-sustaining, producing individuals that will in turn disperse and cause further population spread [60]. In the short term, spreading outwards to locations immediately surrounding the newly colonised location will improve population robustness. In the longer term, a large number of correspond to all of these processes.

\section{Figure I}

Figure I. Schematic representation of range-shift processes and their relationship with the trait categories we suggest (Box 2). We do not suggest that there is an exclusive correspondence between a given trait category and range-shift process. Rather, we identify most directly informative. Note that we are considering species traits and not their interaction with the environment, e.g., we do not include the effect that climate-driven resource limitation could have on emigration. 
We propose seven trait categories related to range-shift processes (Figure I). Trade-offs and interactions between traits mean that some categories cannot be tied exclusively to one range-shift process. We highlight traits addressed by studies in Table 1. First, site (in)fidelity corresponds to emigration, and can be informed by migration (migrants show fidelity to breeding and over-wintering sites between years [8]), and breeding behaviour (social or territorial) that encourages individuals to remain at natal locations or to disperse to new breeding territories [61]. Sessile taxa can also have traits that correspond to site (in)fidelity, for example plants can time seed shed to maximise dispersal by animals [54]. Second, movement ability corresponds directly to the movement process, and for plants can be informed by properties related to dispersal vectors [19]. In animals, movement can be informed by natal dispersal [13] and by behaviours such as migratory status [62], home ranging area [37], or flight period length [63], and morphologies such as wing or leg length [64]. Third, small population effects hinder establishment, and particularly occur in animals that rely on group behaviour for breeding, resource acquisition, or predator avoidance [41], and in plants that can reproduce vegetatively and self-pollinate [19]. Fourth, persistence in unfavourable climatic conditions aids establishment under climate change because newly colonised locations can fluctuate in climatic suitability before becoming consistently suitable for a given species $[65,66]$. This category can be informed in plants by seed-bank persistence [19], and in animals by 'sleep' (e.g. hibernation, dormancy) and 'hide' (use of burrows, caves, tree-holes) behaviours that might allow species to 'wait out' unfavourable periods [67] or by traits indicating the importance of each reproductive event to lifetime reproduction (e.g. longevity). Fifth, ecological generalisation aids establishment and proliferation by increasing resource availability, and includes diet breadth, land-cover types 
will rapidly achieve high local abundances (aiding establishment), thus driving emigration

424 (aiding proliferation). Reproductive strategy can be informed by traits linked to the number, timing and degree of investment in each reproductive event $[10,27]$. Seventh, low competitive ability hinders establishment when competition with incumbent individuals occurs, and hinders proliferation by slowing the growth of already-established populations. Competitive ability could be informed by population traits (e.g. local density [34]) the number of co-occurring congeners [68]), by brain size in animals [27] and by leaf-economic traits in plants $[44,69]$.

Box 3. Case studies applying the predictive trait framework to evaluate range-shift capacities

We examine pairs of species that are predicted to potentially undergo climate-driven range shift in the $21^{\text {st }}$ century (Table I). We show how different traits can be used to inform the likelihood or speed of range shifts. There are multiple ways in which trait categories could be combined to determine range-shift ability. Here we classify the trait values for each species as High, Moderate or Low depending on the species' trait value relative to values for related species. We averaged the results for the best-supported traits for a given taxa. For the sake of illustration, we consider that a trait category is supported when at least three studies in Table 1 found a significant relationship between the trait category and a response variable. Other approaches are possible, such as i) assigning a numeric score to the results in each trait category and summing across all, or the best-supported categories, ii) two species can be compared by summing the number of differences (positive and negative) between results in each, or the best-supported, trait category. We make no recommendations as to 
species. Both Populus nigra and Carpinus betulus are predicted to gain climatically suitable

areas to the north of their range (Figure II), but Carpinus betulus is more likely to colonise

this area. Sylvia cantillans is predicted to gain proportionally more climatically suitable area

Table I. Case studies illustrating the application of our framework to improve range-shift evaluations under climate change.

\begin{tabular}{|c|c|c|c|}
\hline Taxa & \multicolumn{2}{|c|}{ Plants (trait data from [19]) } & $\begin{array}{c}\text { Median values for } \\
\text { native European } \\
\text { trees }\end{array}$ \\
\hline Species & Carpinus betulus & Populus nigra & \\
\hline Movement ability & $\begin{array}{l}\text { High (estimated } 1500 \mathrm{~m} \text {, bird } \\
\text { and mammal seed dispersal, } \\
\text { seed mass } 53 \mathrm{mg} \text { ) }\end{array}$ & $\begin{array}{l}\text { Moderate (estimated } 15 \mathrm{~m} \text {, } \\
\text { wind seed dispersal, low } \\
\text { seed mass } 0.81 \mathrm{mg} \text { ) }\end{array}$ & $\begin{array}{l}\text { Dispersal 500m } \\
\text { Seed mass } 25 \mathrm{mg}\end{array}$ \\
\hline $\begin{array}{l}\text { Persistence in } \\
\text { unfavourable } \\
\text { climatic conditions }\end{array}$ & $\begin{array}{l}\text { Moderate (seed bank } \\
\text { persistence } 1-5 \text { years) }\end{array}$ & $\begin{array}{l}\text { Low (seed bank } \\
\text { persistence }<1 \text { year) }\end{array}$ & \\
\hline $\begin{array}{l}\text { Ecological } \\
\text { generalisation }\end{array}$ & $\begin{array}{l}\text { High ( } 2.19 \text { vegetation types } \\
\text { occupied) }\end{array}$ & $\begin{array}{l}\text { Low (1.2 vegetation types } \\
\text { occupied) }\end{array}$ & $\begin{array}{l}1.86 \text { vegetation } \\
\text { types }\end{array}$ \\
\hline $\begin{array}{l}\text { Reproductive } \\
\text { strategy }\end{array}$ & $\begin{array}{l}\text { High (perennial tree species, } \\
\text { age of first flowering } 15 \\
\text { years) }\end{array}$ & $\begin{array}{l}\text { Moderate (perennial tree } \\
\text { species, age of first } \\
\text { flowering } 6 \text { years) }\end{array}$ & 8 years \\
\hline Competitive ability & $\begin{array}{l}\text { High/moderate (mean height } \\
15 \mathrm{~m}, \text { SLA } 24 \mathrm{~mm}^{2} / \mathrm{mg} \text { ) }\end{array}$ & $\begin{array}{l}\text { High/moderate (mean } \\
\text { height } 50 \mathrm{~m} \text {, SLA } 11 \\
\mathrm{~mm}^{2} / \mathrm{mg} \text { ) }\end{array}$ & $\begin{array}{l}\text { Height } 20 \mathrm{~m} \\
\text { SLA } 10 \mathrm{~mm}^{2} / \mathrm{mg}\end{array}$ \\
\hline $\begin{array}{l}\text { Resulting range- } \\
\text { shift ability }\end{array}$ & High & Moderate / Low & \\
\hline Taxa & Birds (trait da & from [70]) & $\begin{array}{c}\text { Median values for } \\
\text { native European } \\
\text { passerines }\end{array}$ \\
\hline Species & Corvus monedula & Sylvia cantillans & \\
\hline Movement ability & $\begin{array}{l}\text { High (natal dispersal } 8.6 \mathrm{~km} \text {, } \\
\text { seasonal migrant) }\end{array}$ & $\begin{array}{l}\text { Moderate (seasonal } \\
\text { migrant) }\end{array}$ & $8.45 \mathrm{~km}$ \\
\hline $\begin{array}{l}\text { Ecological } \\
\text { generalisation }\end{array}$ & $\begin{array}{l}\text { High (omnivorous and } \\
\text { opportunistic, high habitat } \\
\text { breadth 5.4) }\end{array}$ & $\begin{array}{l}\text { Low (omnivorous, low } \\
\text { habitat breadth 1.25) }\end{array}$ & $\begin{array}{l}3.4 \text { vegetation } \\
\text { types }\end{array}$ \\
\hline $\begin{array}{l}\text { Reproductive } \\
\text { strategy }\end{array}$ & $\begin{array}{l}\text { Low (large-bodied: } 248 \mathrm{~g}, \\
\text { late reproducing: year 2, }\end{array}$ & $\begin{array}{l}\text { Moderate (small-body: } \\
9.8 \text { g, early reproducing: }\end{array}$ & $\begin{array}{l}\text { Body mass } 21 \mathrm{~g} \\
\text { Sexual maturity }\end{array}$ \\
\hline
\end{tabular}




\begin{tabular}{|l|l|l|l|}
\hline & $\begin{array}{l}\text { average clutch size 4.46, } 1 \\
\text { brood per year) }\end{array}$ & $\begin{array}{l}\text { year 1, small clutches: } \\
3.86,2 \text { broods per year) }\end{array}$ & $\begin{array}{l}\text { year 1 } \\
\text { Clutch size 4.6 } \\
\text { Clutches/year 1.7 }\end{array}$ \\
\hline Competitive ability & $\begin{array}{l}\text { High (large brain size : body } \\
\text { mass ratio) }\end{array}$ & $\begin{array}{l}\text { Moderate (small brain } \\
\text { size : body mass ratio) }\end{array}$ & \\
\hline $\begin{array}{l}\text { Resulting range- } \\
\text { shift ability }\end{array}$ & High & Moderate / Low & \\
\hline
\end{tabular}

455 Figure II. Current distributions and areas predicted climatically suitable for case study

456 species in 2071-2100 (see section C in Appendix S1 for details of distributions and forecasts).

457 Black dots are currently occupied, blue areas are climatically suitable in the future, and

458 yellow areas are climatically unsuitable. 
1 Garcia, R.A. et al. (2014) Multiple dimensions of climate change and their implications for biodiversity. Science (New York, N.Y.) 344, 1247579-1247579

2 Anderson, R.P. (2013) A framework for using niche models to estimate impacts of climate change on species distributions. Annals of the New York Academy of Sciences 1297, 828

3 Márquez, A.L. et al. (2011) Combining climate with other influential factors for modelling the impact of climate change on species distribution. Clim. Chang. 108, 135-157

4 Foden, W.B. et al. (2013) Identifying the world's most climate change vulnerable species: a systematic trait-based assessment of all birds, amphibians and corals. PLOS ONE 8 , e65427

5 Triviño, M. et al. (2013) Risk assessment for lberian birds under global change. Biol. Conserv. $168,192-200$

6 Garcia, R.A. et al. (2014) Matching species traits to projected threats and opportunities from climate change. J. Biogeogr. 41, 724-735

7 Pearson, R. et al. (2014) Life history and spatial traits predict extinction risk due to climate change. Nat. Clim. Change 4, 217-221

8 Bensch, S. (1999) Is the range size of migratory birds constrained by their migratory program? J. Biogeogr. 26, 1225-1235

9 Laube, l. et al. (2013) Towards a more mechanistic understanding of traits and range sizes. Global Ecol. Biogeogr. 22, 233-241

10 Angert, A.L. et al. (2011) Do species' traits predict recent shifts at expanding range edges? Ecol. Lett. 14, 677-689

11 Mattila, N. et al. (2011) Ecological correlates of distribution change and range shift in butterflies. Insect Conserv. Diver. 4, 239-246

12 Auer, S.K. and King, D.I. (2014) Ecological and life-history traits explain recent boundary shifts in elevation and latitude of western North American songbirds. Global Ecol. Biogeogr. 23, 867-875

13 Bradshaw, C.J.A. et al. (2014) Predictors of contraction and expansion of area of occupancy for British birds. P. Roy. Soc. B-Biol. Sci. 281, 20140744

14 Sunday, J.M. et al. (2015) Species traits and climate velocity explain geographic range shifts in an ocean warming hotspot. Ecol. Lett. In press

15 Tayleur, C. et al. (2015) Swedish birds are tracking temperature but not rainfall: evidence from a decade of abundance changes. Global Ecol. Biogeogr. 24, 859-872

16 Lenoir, J. and Svenning, J.C. (2015) Climate-related range shifts - a global multidimensional synthesis and new research directions. Ecography 38, 15-28

17 Kunin, W.E. and Gaston, K.J. (1997) The biology of rarity: causes and consequences of rarecommon differences. Springer

18 Svenning, J.-C. et al. (2008) Postglacial dispersal limitation of widespread forest plant species in nemoral Europe. Ecography 31, 316-326

19 Estrada, A. et al. (2015) Species' intrinsic traits inform their range limitations and vulnerability under environmental change. Global Ecol Biogeogr 24, 849-858

20 Warren, D.L. et al. (2014) Mistaking geography for biology: inferring processes from species distributions. Trends Ecol. Evol. 29, 572-580

21 Sunday, J.M. et al. (2015) Species traits and climate velocity explain geographic range shifts in an ocean-warming hotspot. Ecol Lett, n/a-n/a

22 Svenning, J.-C. and Skov, F. (2004) Limited filling of the potential range in European tree species. Ecol. Lett. 7, 565-573

23 Dullinger, S. et al. (2012) Post-glacial migration lag restricts range filling of plants in the European Alps. Global Ecol. Biogeogr. 21, 829-840 
24 Hortal, J. et al. (2011) Ice age climate, evolutionary constraints and diversity patterns of European dung beetles. Ecol Lett 14, 741-748

25 Wisz, M.S. et al. (2013) The role of biotic interactions in shaping distributions and realised assemblages of species: implications for species distribution modelling. Biol. Rev. 88, 15-30

26 Bucharova, A. and Van Kleunen, M. (2009) Introduction history and species characteristics partly explain naturalization success of North American woody species in Europe. J. Ecol. 97, 230-238

27 Sol, D. et al. (2012) Unraveling the life history of successful invaders. Science 337, 580-583

28 Caplat, P. et al. (2013) Movement, impacts and management of plant distributions in response to climate change: insights from invasions. Oikos 122, 1265-1274

29 Moran, E.V. and Alexander, J.M. (2014) Evolutionary responses to global change: lessons from invasive species. Ecol. Lett. 17, 637-649

30 Mack, R.N. et al. (2000) Biotic invasions: causes, epidemiology, global consequences, and control. Ecological Applications 10, 689-710

31 Richardson, D.M. and Pysek, P. (2012) Naturalization of introduced plants: ecological drivers of biogeographical patterns. The New phytologist 196, 383-396

32 Williamson, M. (1996) Biological Invasions. Chapman \& Hall

33 Jeschke, J.M. and Strayer, D.L. (2005) Invasion success of vertebrates in Europe and North America. PNAS 102, 7198-7202

34 Blackburn, T.M. and Jeschke, J.M. (2009) Invasion success and threat status: two sides of a different coin? Ecography 32, 83-88

35 Jiguet, F. et al. (2007) Climate envelope, life history traits and the resilience of birds facing global change. Global Change Biol. 13, 1672-1684

36 Seoane, J. and Carrascal, L.M. (2008) Interspecific differences in population trends of Spanish birds are related to habitat and climatic preferences. Global Ecol. Biogeogr. 17, 111-121

37 Collen, B. et al. (2011) Predicting how populations decline to extinction. Phil. Trans. R. Soc. B 366, 2577-2586

38 Gill, J.A. et al. (2001) The buffer effect and large-scale population regulation in migratory birds. Nature $412,436-438$

39 Devictor, V. et al. (2008) Birds are tracking climate warming, but not fast enough. P. Roy. Soc. B-Biol. Sci. 275, 2743-2748

40 Clavero, M. et al. (2011) Climate change or land use dynamics: Do we know what climate change indicators indicate? PLOS ONE 6, e18581

41 Cardillo, M. et al. (2008) The predictability of extinction: biological and external correlates of decline in mammals. P. Roy. Soc. B-Biol. Sci. 275, 1441-1448

42 Schurr, F.M. et al. (2007) Colonization and persistence ability explain the extent to which plant species fill their potential range. Global Ecol. Biogeogr. 16, 449-459

43 Van der Veken, S. et al. (2007) Life-history traits are correlated with geographical distribution patterns of western European forest herb species. J. Biogeogr. 34, 17231735

44 J.P., G. (1977) Evidence for the existence of three primary strategies in plants and its relevance to ecological and evolutionary theory. The American Naturalist 111, 11691194

45 Altwegg, R. et al. (2013) Density-dependent dispersal and the speed of range expansions. Divers. Distrib. 19, 60-68

46 Catullo, R.A. et al. (2015) Extending spatial modelling of climate change responses beyond the realized niche: estimating, and accommodating, physiological limits and adaptive evolution. Global Ecol. Biogeogr. 24, 1192-1202

47 Jongejans, E. et al. (2011) Importance of individual and environmental variation for invasive species spread: a spatial integral projection model. Ecology 92, 86-97 
48 Gaston, K.J. and Fuller, R.A. (2009) The sizes of species' geographic ranges. J. Appl. Ecol. 46, 1-9

49 Aarssen, L. (1984) On the distinction between niche and competitive ability: Implications for coexistence theory. Acta Biotheor 33, 67-83

50 Bartomeus, I. et al. (2013) Historical changes in northeastern US bee pollinators related to shared ecological traits. PNAS 110, 4656-4660

51 Westoby, M. (1998) A leaf-height-seed (LHS) plant ecology strategy scheme. Plant Soil 199, 213-227

52 Violle, C. et al. (2007) Let the concept of trait be functional! Oikos 116, 882-892

53 Travis, J.M.J. et al. (2012) Modelling dispersal: an eco-evolutionary framework incorporating emigration, movement, settlement behaviour and the multiple costs involved. Methods Ecol. Evol. 3, 628-641

54 Warren, R.J. et al. (2014) Competition as a mechanism structuring mutualisms. J. Ecol. 102, 486-495

55 Bocedi, G. et al. (2014) Mechanistic modelling of animal dispersal offers new insights into range expansion dynamics across fragmented landscapes. Ecography 37, 1240-1253

56 Baguette, M. (2003) Long distance dispersal and landscape occupancy in a metapopulation of the cranberry fritillary butterfly. Ecography 26, 153-160

57 Coutts, S. et al. (2011) What are the key drivers of spread in invasive plants: dispersal, demography or landscape: and how can we use this knowledge to aid management? Biol. Invasions 13, 1649-1661

58 Brederveld, R.J. et al. (2011) Dispersal as a limiting factor in the colonization of restored mountain streams by plants and macroinvertebrates. J. Appl. Ecol. 48, 1241-1250

59 Hampe, A. (2011) Plants on the move: The role of seed dispersal and initial population establishment for climate-driven range expansions. Acta Oecol. 37, 666-673

60 Blackburn, T.M. et al. (2011) A proposed unified framework for biological invasions. Trends Ecol. Evol. 26, 333-339

61 Møller, A.P. (2006) Sociality, age at first reproduction and senescence: comparative analyses of birds. J. Evol. Biol. 19, 682-689

62 Cassey, P. et al. (2004) Global patterns of introduction effort and establishment success in birds. P. Roy. Soc. B-Biol. Sci. 271, S405-S408

63 Pöyry, J. et al. (2009) Species traits explain recent range shifts of Finnish butterflies. Global Change Biol. 15, 732-743

64 Bohning-Gaese, K. et al. (2006) Range size: Disentangling current traits and phylogenetic and biogeographic factors. Am. Nat. 167, 555-567

65 Early, R. and Sax, D.F. (2011) Analysis of climate paths reveals potential limitations on species range shifts. Ecol. Lett. 14, 1125-1133

66 Jackson, S.T. et al. (2009) Ecology and the ratchet of events: climate variability, niche dimensions, and species distributions. PNAS 106, 19685-19692

67 Liow, L.H. et al. (2009) Lower extinction risk in sleep-or-hide mammals. Am. Nat. 173, 264272

68 Laube, I. et al. (2013) Intra-generic species richness and dispersal ability interact to determine geographic ranges of birds. Global Ecol. Biogeogr. 22, 223-232

69 Hamilton, M.A. et al. (2005) Life-history correlates of plant invasiveness at regional and continental scales. Ecol. Lett. 8, 1066-1074

70 Estrada, A. et al. (In prep) What can life-history traits tell us about species' range-shift responses climate change? A multi-taxon approach.

$71 \mathrm{Zhu}$, K. et al. (2012) Failure to migrate: lack of tree range expansion in response to climate change. Global Change Biol. 18, 1042-1052

72 Grossenbacher, D. et al. (2015) Geographic range size is predicted by plant mating system. Ecol. Lett. 18, 706-713 
73 Gove, A.D. et al. (2009) Dispersal traits linked to range size through range location, not dispersal ability, in Western Australian angiosperms. Global Ecol. Biogeogr. 18, 596606

74 Thompson, K. et al. (1999) Range size, dispersal and niche breadth in the herbaceous flora of central England. J. Ecol. 87, 150-155

75 Nogués-Bravo, D. et al. (2014) Phenotypic correlates of potential range size and range filling in European trees. Perspect. Plant Ecol. Evol. Syst. 16, 219-227

76 Walker, K.J. and Preston, C.D. (2006) Ecological predictors of extinction risk in the Flora of Lowland England, UK. Biodivers. Conserv. 15, 1913-1942

77 Forsyth, D.M. et al. (2004) Climatic suitability, life-history traits, introduction effort, and the establishment and spread of introduced mammals in Australia. Conserv. Biol. 18, 557569

78 Munguía, M. et al. (2008) Dispersal limitation and geographical distributions of mammal species. J. Biogeogr. 35, 1879-1887

79 Reif, J. et al. (2010) Population changes in Czech passerines are predicted by their lifehistory and ecological traits. Ibis 152, 610-621

80 Hoare, J.M. et al. (2012) Can correlated population trends among forest bird species be predicted by similarity in traits? Wildlife Research 39, 469-477

81 Kotiaho, J.S. et al. (2005) Predicting the risk of extinction from shared ecological characteristics. PNAS 102, 1963-1967 


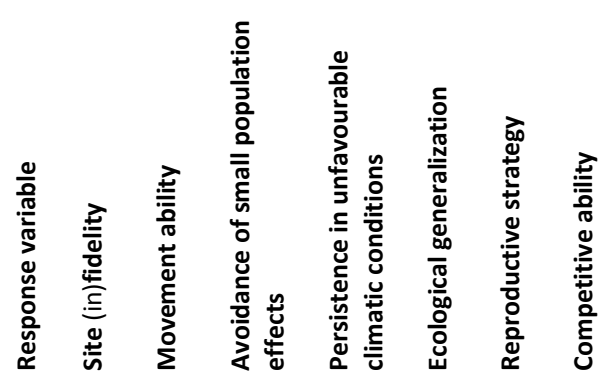

\begin{tabular}{|c|c|c|c|c|c|c|c|c|c|c|c|}
\hline Taxon & 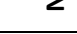 & Location & 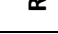 & 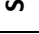 & 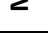 & & & & - & & Reference \\
\hline Alpine plants & 133 & Switzerland & $\mathrm{RS}$ & & $x$ & $\mathrm{x}$ & & $x$ & & & {$[10]^{\mathrm{P}}$} \\
\hline Forest plants & 92 & USA & $\mathrm{RS}$ & & $x$ & & & & & & $*[71]$ \\
\hline Plants & 734 & Global & $\mathrm{RZ}$ & & & + & & & & & $*[72]^{\mathrm{P}}$ \\
\hline Plants & 1276 & Europe & $\mathrm{RZ}$ & & + & $x$ & + & + & - & + & {$[19]^{P}$} \\
\hline Angiosperms & 524 & Australia & $\mathrm{RZ}$ & & $x$ & & & & $x$ & & {$[73]^{\mathrm{P}}$} \\
\hline Herbaceous flora & 263 & Central England & $\mathrm{RZ}$ & & + & & & + & & & {$[74]^{\mathrm{P}}$} \\
\hline Forest plants & 273 & W Europe & $\mathrm{RZ}$ & & + & & + & & & & {$[43]^{\mathrm{P}}$} \\
\hline Plants & 1276 & Europe & RF & & + & $x$ & + & + & - & + & {$[19]^{\mathrm{P}}$} \\
\hline Plants & 183 & Austrian Alps & RF & & + & & & + & & $x$ & $*[23]^{\mathrm{P}}$ \\
\hline Plants & 37 & Fynbos biome & RF & & + & & + & & & + & {$[42]^{\mathrm{P}}$} \\
\hline Trees & 48 & Europe & $\mathrm{RF}$ & & + & & & & & & {$[75]^{\mathrm{P}}$} \\
\hline Trees & 55 & Europe & $\mathrm{RF}$ & & & & & & $x$ & $x$ & {$[22]^{\mathrm{P}}$} \\
\hline Plants & 150 & E Australia & IS & & + & & & & & + & {$[69]^{P}$} \\
\hline Woody plants & 278 & N America and Europe & IS & & + & $x$ & $x$ & + & - & + & {$[26]$} \\
\hline Plants & 898 & Lowland England & ER & & $x$ & & & + & $x$ & $\mathrm{x}$ & [76] \\
\hline Mammals & 28 & NW America & $\mathrm{RS}$ & & & & $x$ & $x$ & $x$ & & {$[10]^{\mathrm{P}}$} \\
\hline Mammals & 23 & Australia & $\mathrm{RZ}$ & $x$ & $x$ & & - & + & + & & {$[77]^{\mathrm{P}}$} \\
\hline Endemic mammals & 89 & Mexico & $\mathrm{RF}$ & & $x$ & & & $x$ & $x$ & & $*[78]$ \\
\hline Mammals & 40 & Australia & IS & + & - & & $x$ & + & $x$ & & {$[77]^{\mathrm{P}}$} \\
\hline Mammals & 292 & USA & $A C$ & & $x$ & & & $x$ & $x$ & & {$[37]^{\mathrm{P}}$} \\
\hline Mammals & 372 & Global & ER & & - & $x$ & & + & + & + & {$[41]^{\mathrm{P}}$} \\
\hline Birds & 254 & N America & RS & & $x$ & & & - & $x$ & & {$[10]^{\mathrm{P}}$} \\
\hline Birds & 97 & UK & RS & & + & & & & + & & {$[13]^{\mathrm{P}}$} \\
\hline Songbirds & 40 & N America & RS & $x$ & $x$ & & & - & - & & {$[12]^{\mathrm{P}}$} \\
\hline Sylvia warblers & 26 & Global & $\mathrm{RZ}$ & & + & & & - & $x$ & & {$[64]^{P}$} \\
\hline Passerines & 165 & Global & $\mathrm{RZ}$ & - & + & & & + & + & & {$[9]^{\mathrm{P}}$} \\
\hline Birds & 23 & Palaearctic $^{a}$ & RF & & + & & & $x$ & & + & {$[68]^{\mathrm{P}}$} \\
\hline Birds & 1813 & N America and Europe & IS & & & & + & + & + & + & {$[34]$} \\
\hline Birds & 416 & Global & IS & $x$ & $x$ & & & + & $x$ & & {$[62]^{\mathrm{P}}$} \\
\hline Birds & 428 & Global & IS & $x$ & $x$ & $x$ & $x$ & + & $x$ & + & {$[27]^{\mathrm{P}}$} \\
\hline Birds & 71 & France & $A C$ & $x$ & $x$ & & & + & + & & {$[35]^{\mathrm{P}}$} \\
\hline Passerines & 57 & Spain & $A C$ & $x$ & $x$ & & & + & & $x$ & {$[36]$} \\
\hline Passerines & 68 & Czech Republic & $A C$ & $x$ & $x$ & & & - & - & & {$[79]^{P}$} \\
\hline Forest birds & 18 & New Zealand & $A C$ & & & & & $x$ & $x$ & & {$[80]$} \\
\hline Herptiles & 36 & USA & ER & & $x$ & & & + & + & + & [7] \\
\hline Butterflies & 48 & Finland & RS & & + & & & $x$ & & & {$[63]^{P}$} \\
\hline Butterflies & 95 & Finland & $\mathrm{RS}$ & & + & & & + & & & $*[11]$ \\
\hline Odonata & 24 & UK & RS & $x$ & $x$ & & & + & $x$ & & {$[10]^{P}$} \\
\hline Bees & 187 & NE USA & $A C$ & & & $x$ & & + & & & {$[50]^{\mathrm{P}}$} \\
\hline Butterflies & 95 & Finland & ER & & + & & & + & & & $*[81]$ \\
\hline \multirow{3}{*}{\multicolumn{4}{|c|}{$\begin{array}{l}\text { Total + } \\
\text { Total - } \\
\text { Total x }\end{array}$}} & 1 & 16 & 1 & 5 & 20 & 7 & 9 & \\
\hline & & & & 1 & 2 & 0 & 1 & 3 & 5 & 0 & \\
\hline & & & & 8 & 16 & 7 & 4 & 7 & 13 & 5 & \\
\hline
\end{tabular}


637 summary of the results. An * before the reference indicates that predictive traits were tested individually, not in concert with other traits. A ' $P$ ' after the reference indicates that the study accounts for the phylogeny of the species. ' $a$ ': the study area of this reference is Palaearctic, Afrotropics and Indo-Malaya. References are sorted by taxa (plants, mammals, birds, herptiles and invertebrates) and then by the response variable. Response variables are as follows. RS: range shift, RZ: range size, RF: range filling, IS: introduction (naturalisation) or invasion success, AC: abundance change, ER: extinction risk. + indicates positive relationship, - indicates negative relationship, $\mathrm{x}$ indicates no relationship, an empty cell means that the trait was not tested. In all cases ' + ' indicates a greater capacity to undergo range shifts. Thus, for AC ' + ' corresponds to positive population growth, for ER ' + ' corresponds to low extinction risk.

647 For each of the trait categories, a ' + ' sign indicates that the relationship between trait and metric indicates the following increases range-shift capacities. Site (in)fidelity: a high likelihood of leaving the natal location; movement: strong movement ability; avoidance of small population sizes: ability to avoid small population effects; persistence in unfavourable climatic conditions: ability to persist in unfavourable conditions; ecological generalization: ecological generalists; reproductive strategy: an ' $r$ ' strategy; competitive ability: strong competitors (see Box 2 for more details). Predictive traits and further rationales for each of the seven categories are detailed in Appendix S1 (section B). 